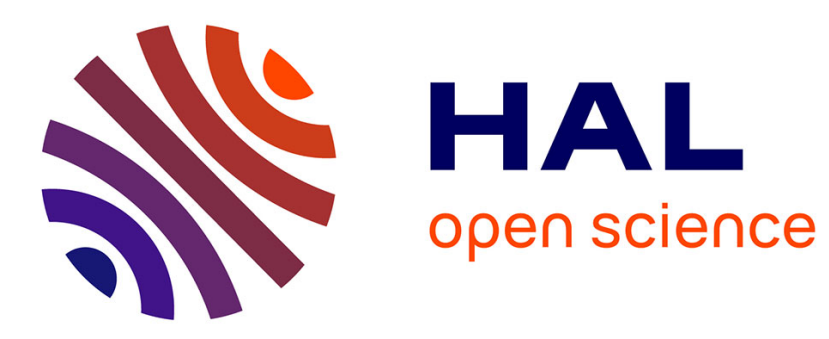

\title{
Complementarity between Solar and Wind Energy Potentials in Benin Republic
}

Maurel Richy Gnandji, François Fifatin, Amèdédjihundé Hounnou, Frédéric Dubas, Didier Chamagne, Christophe Espanet, Antoine Vianou

\section{- To cite this version:}

Maurel Richy Gnandji, François Fifatin, Amèdédjihundé Hounnou, Frédéric Dubas, Didier Chamagne, et al.. Complementarity between Solar and Wind Energy Potentials in Benin Republic. Advanced Engineering Forum, 2018, 1, pp.128 - 138. hal-02299968

\section{HAL Id: hal-02299968 https://hal.science/hal-02299968}

Submitted on 29 Sep 2019

HAL is a multi-disciplinary open access archive for the deposit and dissemination of scientific research documents, whether they are published or not. The documents may come from teaching and research institutions in France or abroad, or from public or private research centers.
L'archive ouverte pluridisciplinaire HAL, est destinée au dépôt et à la diffusion de documents scientifiques de niveau recherche, publiés ou non, émanant des établissements d'enseignement et de recherche français ou étrangers, des laboratoires publics ou privés. 


\title{
Complementarity between Solar and Wind Energy Potentials in Benin Republic
}

\author{
Maurel AZA-GNANDJI ${ }^{1, a^{*}}$, François-Xavier FIFATIN ${ }^{1, b}$, A. Hypolite J. \\ HOUNNOU ${ }^{1,2, c}$, Frédéric DUBAS ${ }^{2, d}$, Didier CHAMAGNE ${ }^{2, ~ e, ~}$ \\ Christophe ESPANET ${ }^{3, \mathrm{f}}$ and Antoine VIANOU $^{1, g}$
}

\author{
1Department of Electrical Engineering, Polytechnic School of Abomey-Calavi, University of \\ Abomey-Calavi, 01BP2009 COTONOU, Benin Republic \\ 2Département ENERGIE, FEMTO-ST, CNRS, Univ. Bourgogne Franche-Comté, F90000 Belfort, France \\ ${ }^{3}$ Univ. Bourgogne Franche-Comté, F90000 Belfort, France \\ a maurel.aza@gmail.com, bfxfifatin@yahoo.fr, ${ }^{c}$ jorhyam@yahoo.fr, ${ }^{\mathrm{d}}$ FDubas@gmail.com, \\ edidier.chamagne@univ-fcomte.fr, ${ }^{\mathrm{f}} \underline{\underline{ }}$ hristophe.espanet@univ-fcomte.fr, ${ }^{\mathrm{g}} \underline{\mathrm{avianou} @ y a h o o . f r}$ \\ * Corresponding Author
}

Keywords: Complementarity, wind energy, solar, Pearson coefficient.

\begin{abstract}
This paper presents a study to show the complementarity between solar and wind energy potentials in Benin Republic. Daily wind speed data in the coast of Cotonou city, precisely in Cadjehoun district, has been used to assess wind energy potential. Solar potential is evaluated using spatio temporal daily solar radiation data covering the country. In this research, we have found the locations offering optimal complementarity between solar and wind energy. The complementarity is measured with Pearson correlation coefficient, which is used as objective function to be minimized. The optimization method used is Particle Swarm Optimization (PSO), which has been implemented in Matlab®. We showed that an optimal complementarity is obtained between the coast of Cotonou in the 'Littoral' department and the central part of the country in the 'Collines' department.
\end{abstract}

\section{Introduction}

Renewable energy technologies are taking an important proportion in the world global energy mix. In fact the part of renewable energy shared in the global energy production was $22 \%$ in 2012 and is predicted to be $29 \%$ by 2040 [1]. World Energy Council reported in 2015 that the contribution of wind and photovoltaic (PV) energies in the global mix was respectively $7 \%$ and $1 \%$ [2].

Despite being free fuel sources, they both have an intermittent nature. Thus, it is not easy to harness them without accurate calculations. In fact, an interesting solution for attenuating their fluctuant nature is to combine them since they have different intermittency nature.

From the literature review, many research have been achieved concerning complementarity between renewable energy sources. In [3], the complementarity between hydro and wind energy have been evaluated in Brazil. A complementarity map was drawn to show the spatiotemporal complementarity between wind and hydro energy sources. Another study have been conducted for offshore wind and hydro energy complementarity in Brazil [4]. This study revealed a good complementarity between offshore wind resources and hydro plants installed in the country. The complementarity was measured using correlation coefficient based on monthly wind speed data and precipitation level. In [5], another study assessed the complementarity between solar and wind energy in China. The spatiotemporal complementarity between wind and solar energy was assessed for several locations in China. This study showed that the combination of solar and wind results in smoother fluctuations of energy than each source considered individually. 
From the previously published papers, the coastal area of Benin Republic is the most favorable for wind energy production [6]-[8]. The country is globally covered regarding solar energy, where the northern and the coastal area are presenting the greatest potentials (see Fig 3). The country is also favorable to micro-/pico-hydro energy because of its many rivers.

It turns out from the analysis of the published papers in general that the mix of complementary sources can contribute to a much stable power generation. Hence, convenient selection of their location is very important to guaranty this complementarity. This research proposes a selection approach of these locations by using an optimization approach. Considering the previous research on wind potential in Benin, we are looking for the optimal placement of a solar farm which can ensure a good complementarity with a wind energy farm in the coastal area of the country.

This paper is structured in three sections, after this introduction. The first section presents the study area and the optimization problem formulation. The next section concerns the results obtained and the last part gives the main achievements of this research.

\section{Material and Methodology}

\section{Study Area and Data}

Benin Republic is a coastal country of West Africa. As presented in Fig 3, the country is bordered by Niger in the North, Burkina-Faso in the North-West, Togo in the South-West and Nigeria in the East. The coastal line of the country is one of the smallest in West Africa with only $121 \mathrm{~km}$ length.

Average daily wind speed is obtained from the database presented in [9]. This database covers the period from 01-01-2013 to 12-31-2013 and is taken at the Cadjehoun (located in Cotonou) airport coordinate position. The proportion of data available is $98.45 \%$. Table 1 presents further information on this dataset.

Table 1: Daily wind speed dataset information.

\begin{tabular}{|l|l|}
\hline Information & Value \\
\hline Type & Wind speed \\
\hline Location & International airport of Cadjehoun - Cotonou \\
\hline Duration & $01-01-2013$ to 12-31-2013 \\
\hline Frequency & Daily \\
\hline Missing data & 6 Days \\
\hline Minimum & $1.5 \mathrm{~m} / \mathrm{s}$ \\
\hline Maximum & $7.45 \mathrm{~m} / \mathrm{s}$ \\
\hline
\end{tabular}

Fig 1 presents the visualization of the daily wind speed data in Cadjehoun airport. From the analysis of this curve, the daily wind speed varies between $1.5 \mathrm{~m} / \mathrm{s}$ and $7.45 \mathrm{~m} / \mathrm{s}$. 


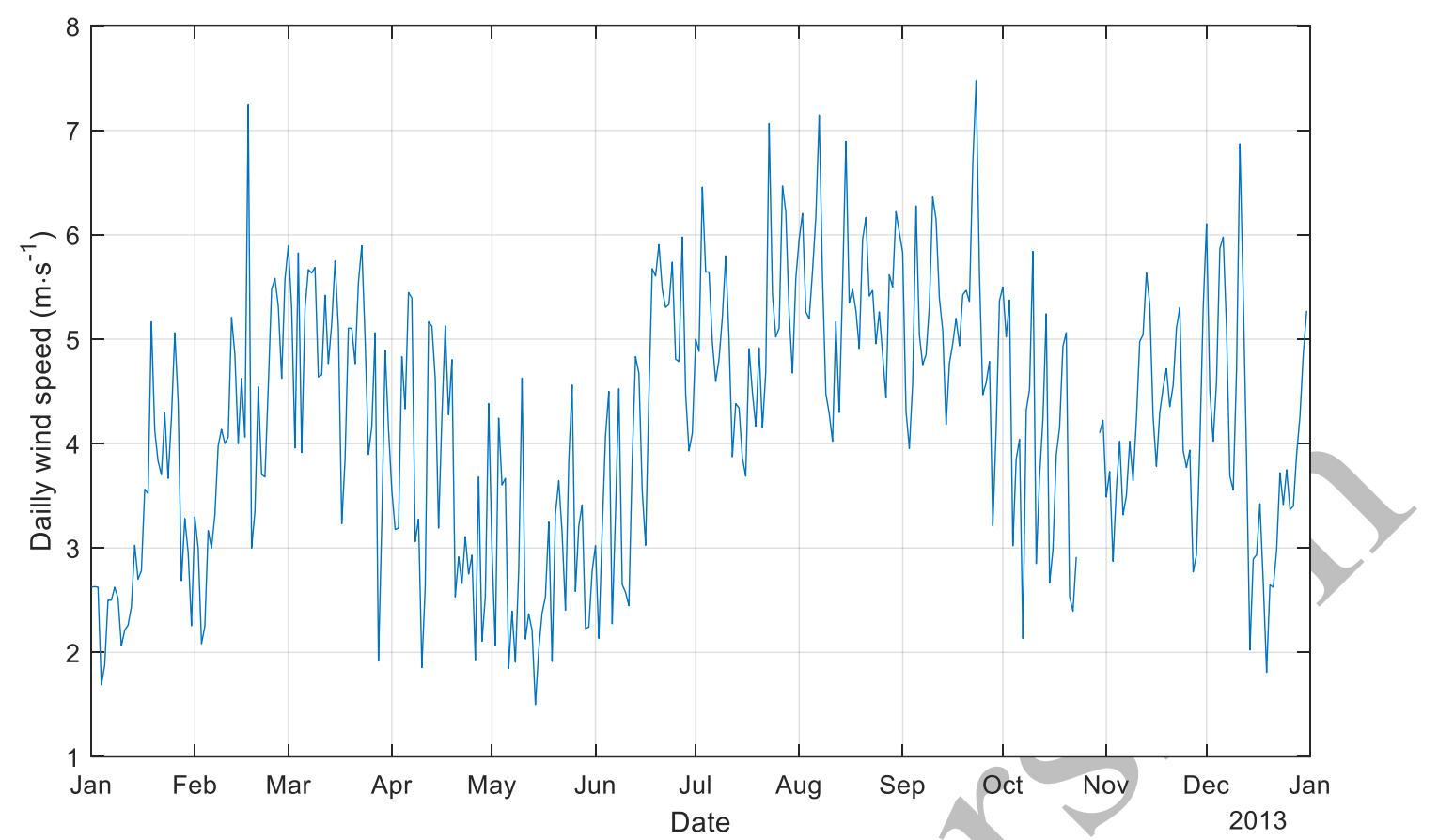

Fig 1: Daily wind speed in Cadjehoun airport.

Wind speed distribution is illustrated in Fig 2 through a histogram. It can be noticed that wind speed occurrence is likely in the range of $5 \mathrm{~m} / \mathrm{s}$ at $10 \mathrm{~m}$ height in Cotonou coast.

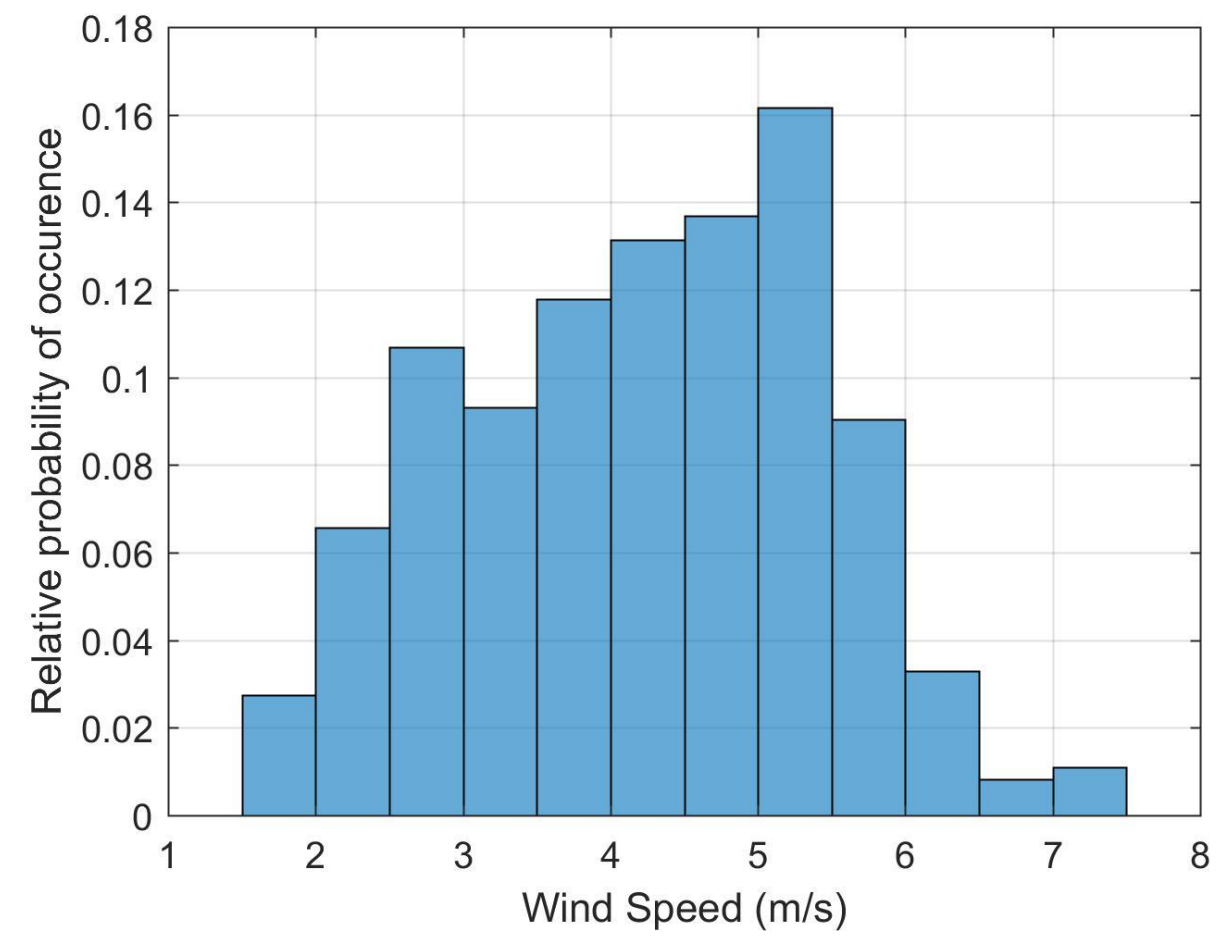

Fig 2: Wind speed relative probability of occurrence at $10 \mathrm{~m}$.

The daily average Direct Normal Irradiation (DNI) is obtained for the same period from [10]. This data covers the surface of the country with a precision of $0.05^{\circ}$ in longitude and $0.05^{\circ}$ in latitude. Further information related to this dataset is presented in Table 2. 
Table 2: Daily solar irradiation dataset information.

\begin{tabular}{|l|l|}
\hline Information & Value \\
\hline Type & DNI \\
\hline Location & Benin \\
\hline Precision (Lon $x$ Lat) & $0.05^{\circ} \times 0.05^{\circ}$ \\
\hline Duration & $01-01-2013$ to $12-31-2013$ \\
\hline Frequency & Daily \\
\hline
\end{tabular}

Heliosat (SARAH) dataset are used for daily wind speed data [10]. The spatial visualization of the yearly mean DNI for 2013 have been computed using Matlab® and is presented in Fig 3. One can notice that the Northern part of the country in general presents the extreme DNI values for the year 2013.

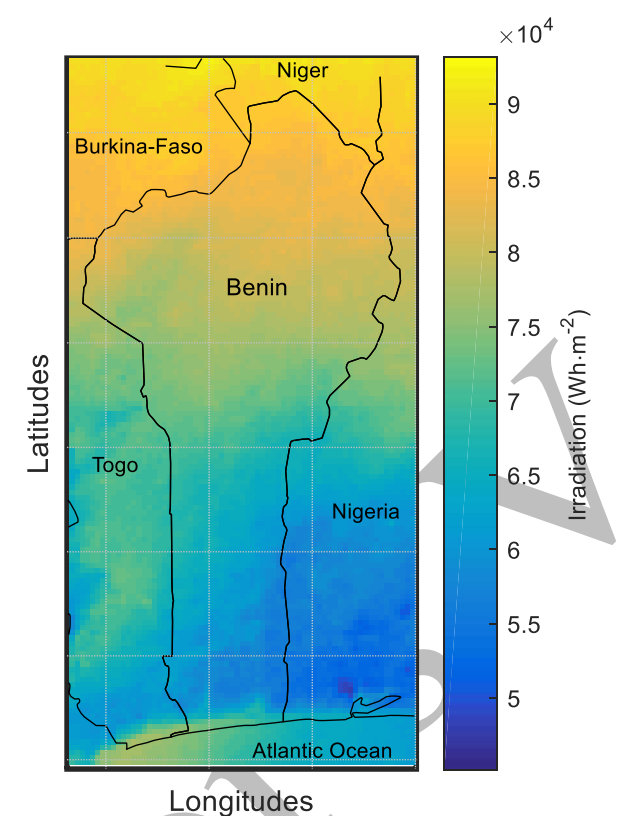

Fig 3: Spatial visualization of DNI for year 2013.

\section{Optimization Problem Formulation}

In order to assess the complementarity between sources, their potential must be modeled. In the literature, a dimensionless index approach is generally used for this purpose [3], [5], [11]. This approach considers that the power fluctuations are due in majority to DNI for solar energy and wind speed for wind energy. Thus, solar potential is obtained by:

$$
P_{\text {sol, } i}=K_{1} I_{i}
$$

where $K_{1}$ represents the dimensionless coefficient related to solar potential and $I_{i}$ the DNI for the $i^{\text {th }}$ day.

The wind energy potential is modeled as:

$$
P_{\text {wind }, i}=K_{2} v_{i}^{3}
$$

where $K_{2}$ represents the dimensionless coefficient related to wind energy potential and $v_{i}$ is the wind speed for the $i^{\text {th }}$ day.

The dimensionless coefficients $K_{1}$ and $K_{2}$ are determined considering the annual production of each source. In this paper, we have considered an annual energy production of $10^{6} \mathrm{kWh}$ by year for each source. The yearly production for wind energy is:

$$
P_{\text {wind }}=\sum_{i} P_{\text {wind }, i}=10^{6}
$$

and the yearly solar production $P_{\text {sol }}$ is given by:

$$
P_{\text {sol }}=\sum_{i} P_{\text {sol, } i}=10^{6}
$$


The dimensionless coefficients $K_{1}$ and $K_{2}$ are obtained by solving (3) and (4).

After modeling each source's potential, the complementarity between them can now be calculated. In the literature, this complementarity can be quantified using correlation coefficients. Thus, the Pearson correlation coefficient is generally used for this purpose [3], [4], [11], [12]. In this paper, this Pearson correlation coefficient is given by:

$$
r=\frac{\sum_{i=1}^{365}\left(P_{\text {wind }, i}-\overline{P_{\text {wind }}}\right) \cdot\left(P_{\text {sol }, i}-\overline{P_{\text {sol }}}\right)}{\sqrt{\sum_{i=1}^{365}\left(P_{\text {wind }, i}-\overline{P_{\text {wind }}}\right)^{2} \cdot \sum_{i=1}^{365}\left(P_{\text {sol }, i}-\overline{P_{\text {sol }}}\right)^{2}}}
$$

where $\overline{P_{\text {wind }}}=\frac{1}{365} \sum_{i=1}^{365} P_{\text {wind, } i}$ represents the annual average of the wind generation and $\overline{P_{\text {sol }}}=\frac{1}{365} \sum_{i=1}^{365} P_{\text {sol, } i}$ represents the annual average of the solar generation.

Because of the spatial variability of the solar resource, the correlation coefficient presented in (5) vary with the geographic coordinates of the solar resource considered. The resulting optimization problem can be formulated as follow:

$$
\min r\left(\text { lat }_{\text {sol }}, \text { lon }_{\text {sol }}\right)=\frac{\sum_{i=1}^{365}\left(P_{\text {wind }, i}-\overline{P_{\text {wind }}}\right) \cdot\left(P_{\text {sol }, i}\left(\text { lat }_{\text {sol }}, \text { lon }_{\text {sol }}\right)-\overline{P_{\text {sol }}\left(\text { lat }_{\text {sol }}, \text { lon }_{\text {sol }}\right)}\right)}{\sqrt{\sum_{i=1}^{365}\left(P_{\text {wind }, i}-\overline{P_{\text {wind }}}\right)^{2} \cdot \sum_{i=1}^{365}\left(P_{\text {sol }, i}\left(\text { lat }_{\text {sol }}, \text { lon }_{\text {sol }}\right)-\overline{P_{\text {sol }}\left(\text { lat }_{\text {sol }}, \text { lon }_{\text {sol }}\right)}\right)^{2}}}
$$

where $l a t_{s o l}$ and $\operatorname{lon}_{\text {sol }}$ are respectively the latitude and the longitude of the solar resource to evaluate.

The constraint for this problem is that the geographical coordinates obtained must fall into Benin land territory. Since the solar radiation dataset is provided with a precision of $0.05^{\circ} \times 0.05^{\circ}$, the solar potential at any coordinate location not matching with the original dataset is obtained by a simple linear interpolation.

\section{PSO Algorithm}

To solve the optimization problem, a PSO is a stochastic population based algorithm. It has been developed by Kennedy and Eberhart in 1995 [13]. A swarm is made of a set of particles moving in the search space. Each particle is characterized by its position and velocity. The position of the particle actually represents a possible configuration of the system to be optimized. The velocity is a corrective value that should be applied to the particle to update its position with respect to the best positions of the swarm. The velocity is obtained by considering the social behavior of the swarm as well as the cognitive behavior of the particle.

In this research, the PSO implemented in Matlab ${ }^{\circledR}$ combines the constriction developed in [14] and the multiple start developed in [15]. In order to tackle divergence of the algorithm, we introduced a memory of the best particle for each initialization of the algorithm. By doing this, the algorithm is forced to search for better positions at each initialization. The flowchart of the algorithm is presented in Fig 4.

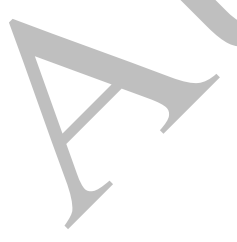




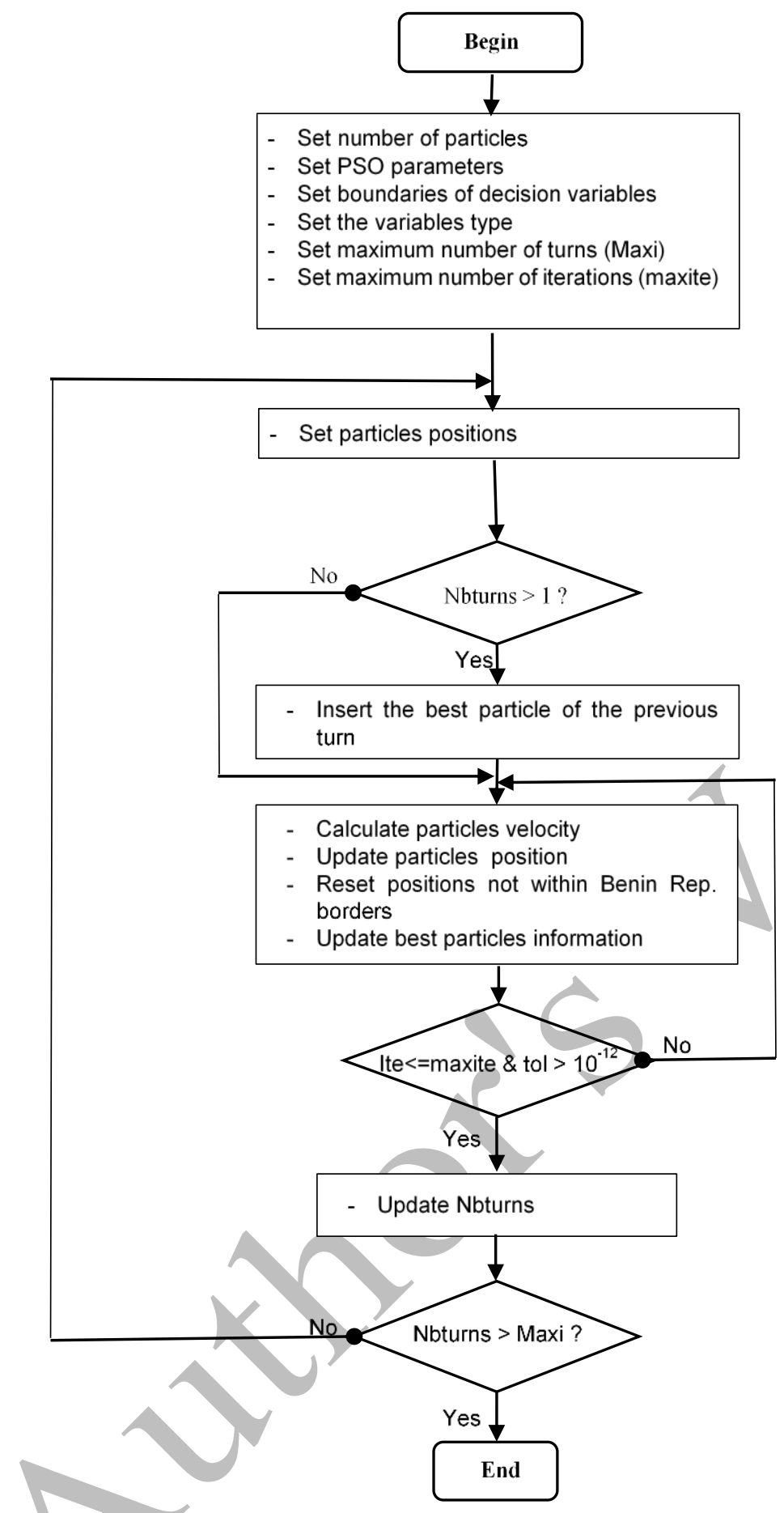

Fig 4: Flowchart of the implemented PSO algorithm.

\section{Results and discussions}

\section{PSO convergence characteristic}

The optimization problem presented is solved using Table 3 values. PSO algorithm coefficients $c_{1}$ and $c_{2}$ are set to 2.05 [15]. The optimization is performed on a 30 particles swarm with 100 iterations and 10 turns. The tolerance is tracked starting from the 10th iteration and the tolerance value is $10^{-12}$. 
Table 3: PSO setup.

\begin{tabular}{|l|l|}
\hline Parameters & Values \\
\hline PSO Coefficient $c_{1}$ & 2.05 \\
\hline PSO Coefficient $c_{2}$ & 2.05 \\
\hline Swarm size & 30 \\
\hline Number of turns & 10 \\
\hline Number of iterations & 100 \\
\hline Tolerance (>10 iterations) & $10^{-12}$ \\
\hline Lower limits [latm, lonm] & {$\left[6^{\circ} \mathrm{N}, 0^{\circ} \mathrm{E}\right]$} \\
\hline Upper limits [latM, lonM] & {$\left[13^{\circ} \mathrm{N}, 4^{\circ} \mathrm{E}\right]$} \\
\hline
\end{tabular}

The convergence characteristic of the PSO algorithm implemented is presented in Fig 5. One can notice that the Pearson correlation coefficient decreases with the iterations. PSO have converged from the 10th iteration with a Pearson correlation coefficient of -0.4291 . Referring to [3], correlation coefficient values are classified into three grades: $|r| \leq 0.4$ for low degree of correlation, $0.4 \leq|\mathrm{r}| \leq 0.7$ stands for remarkable correlation and $|\mathrm{r}| \geq 0.7$ for high degree of correlation. Negative correlation, is recommended for reducing total output power fluctuations [3].Thus, the value -0.4291 is the Pearson coefficient that minimizes the objective function with respect to the environmental data used. This value shows a remarkable inverse correlation between solar and wind resources referring to the interpretation of Pearson correlation coefficient values presented in [3].

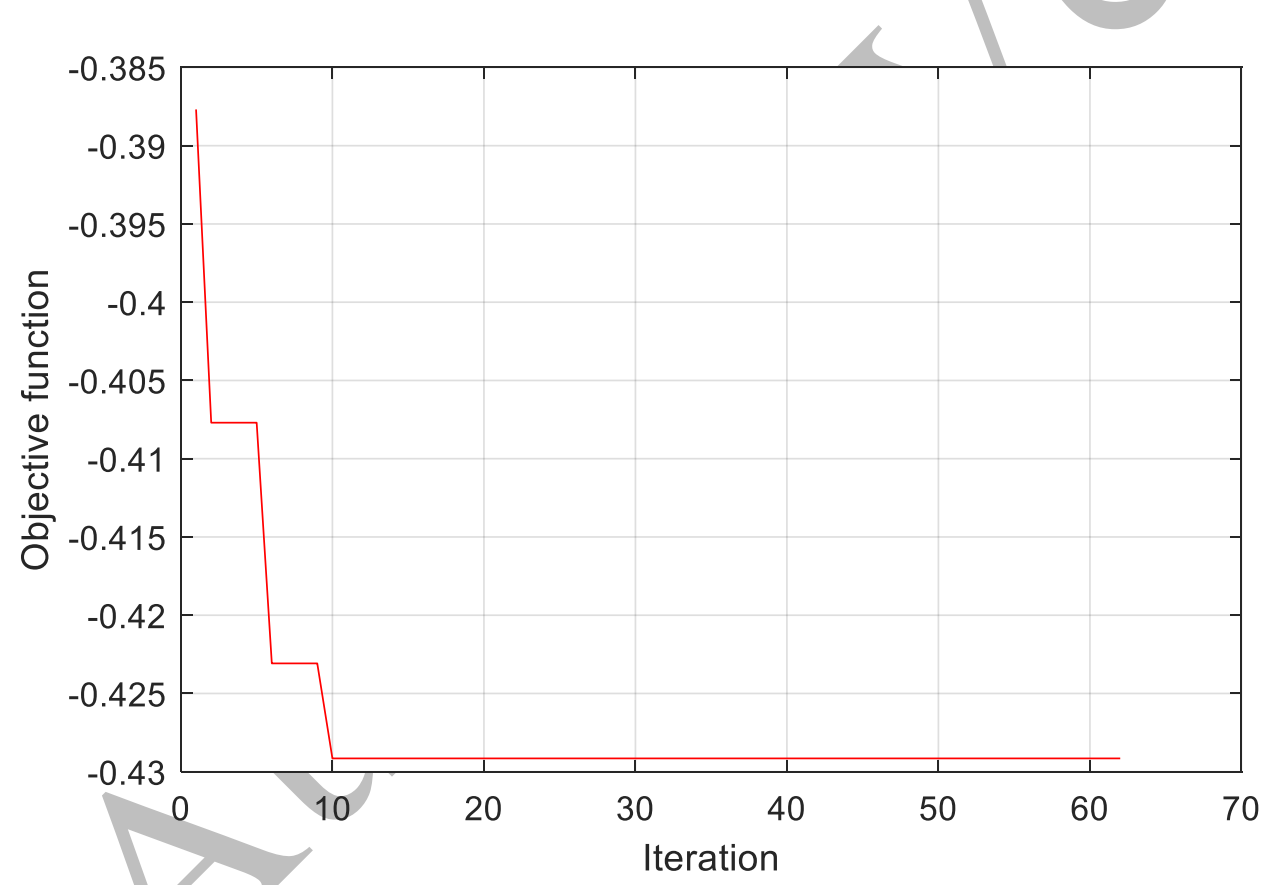

Fig 5: Convergence characteristic of implemented PSO algorithm.

\section{Optimal Location for Wind and Solar Resources}

The position of particles at the last iteration of the algorithm and the location of the wind resource are presented in Fig 6. In this figure blue diamond markers represent each particle's position at the last iteration. Green circle markers give the individual best positions at the last iteration. Red star markers show the global best particle position which is located at longitude $2.66^{\circ} \mathrm{E}$ and latitude $8.29^{\circ} \mathrm{N}$ in the department of 'Collins'. The black square marker point is the location of the wind resource which is located at longitude $2.38^{\circ} \mathrm{E}$ and latitude $6.36^{\circ} \mathrm{N}$ in the department of 'Littoral'. One can notice that the optimal location found for solar resource is not in the area with the greatest solar potential. This can be explained by the fact that complementarity is 
not related to the amplitudes of the potentials of the energy sources and is determined only of the criterion (6).

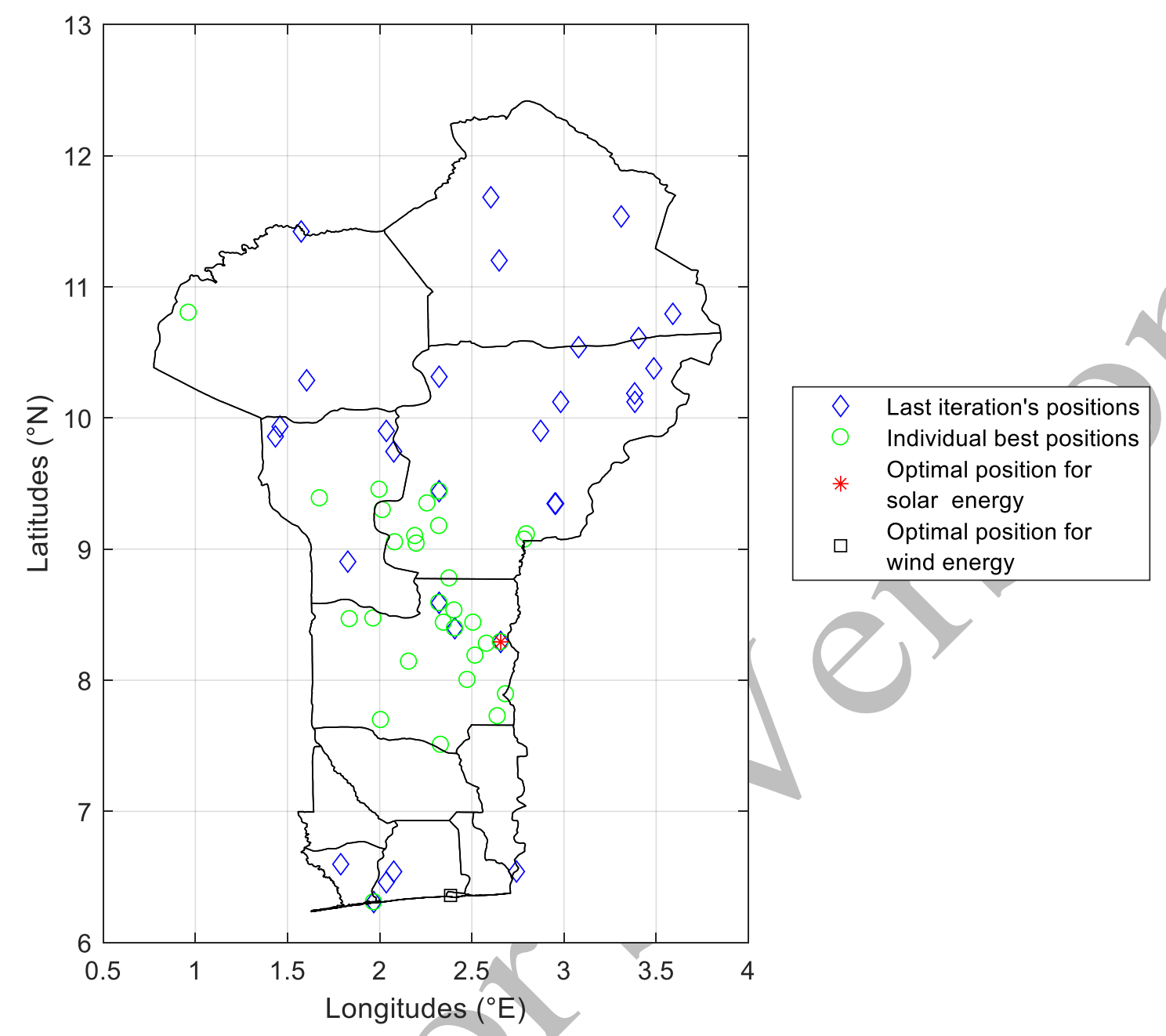

Fig 6: Positions at the last iteration.

DNI at the optimal location have been extracted and is presented in Fig 7. Fig 7-a corresponds to the wind speed variations in Cadjehoun - Cotonou whereas Fig 7-b corresponds to the daily DNI variations for year 2013. One can notice that DNI varies between $3.57 \mathrm{~W} / \mathrm{m}^{2}$ and $311.37 \mathrm{~W} / \mathrm{m}^{2}$ and the lowest values of DNI last from July to September. By doing the same analysis with wind variations in Fig 7, one can notice that the period from July to September is actually the period with the highest wind speed values. 

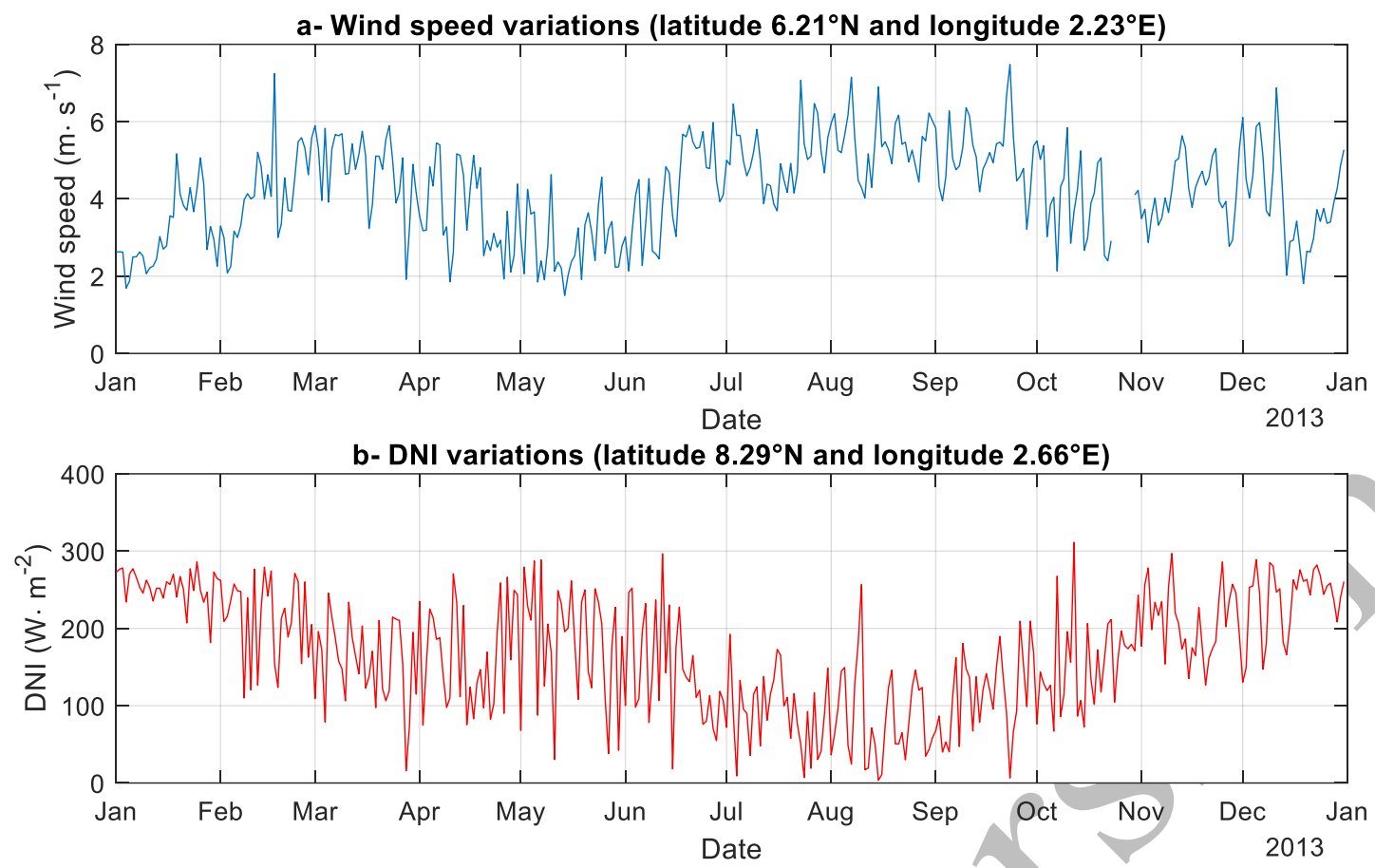

Fig 7: Wind speed variations (latitude $6.21^{\circ} \mathrm{N}$ and longitude $2.23^{\circ} \mathrm{E}$ ) and DNI variations (latitude $8.29^{\circ} \mathrm{N}$ and longitude $2.66^{\circ} \mathrm{E}$ ).

Considering (1) and (2), the power production of solar and wind energy are presented at Fig 8. By analyzing Fig 8 and focusing on wind energy production in dash, it is worth to distinctively notice low production periods and high production periods. Low production periods span from January to February and April to June whereas high productions occur between February and April and also from June to January

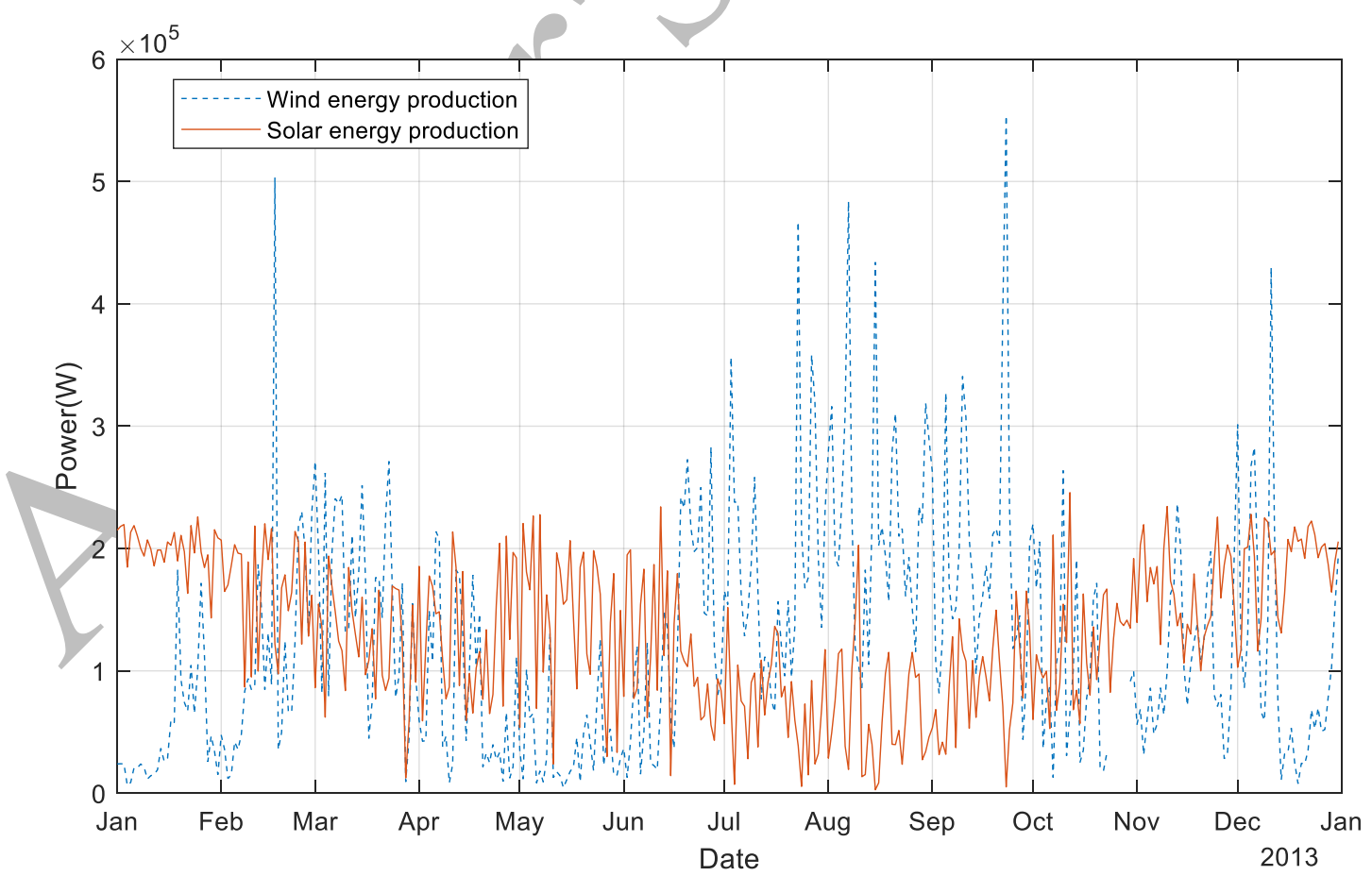

Fig 8: Wind and solar power generation.

On the other hand, solar production is more homogenous regarding the production peak. It is also worth to notice that periods of low wind power production are compensated with PV production 
during the same time considering the PV availability. This is illustrated at Fig 9 which presents the combined production of wind and solar energy sources. From Fig 9, it can be noticed a smooth fluctuation in the total power generation as compared to wind generation alone. Indeed, for a grid connected application, it may be interesting to compensate lacks due to low wind production by combining with PV production.

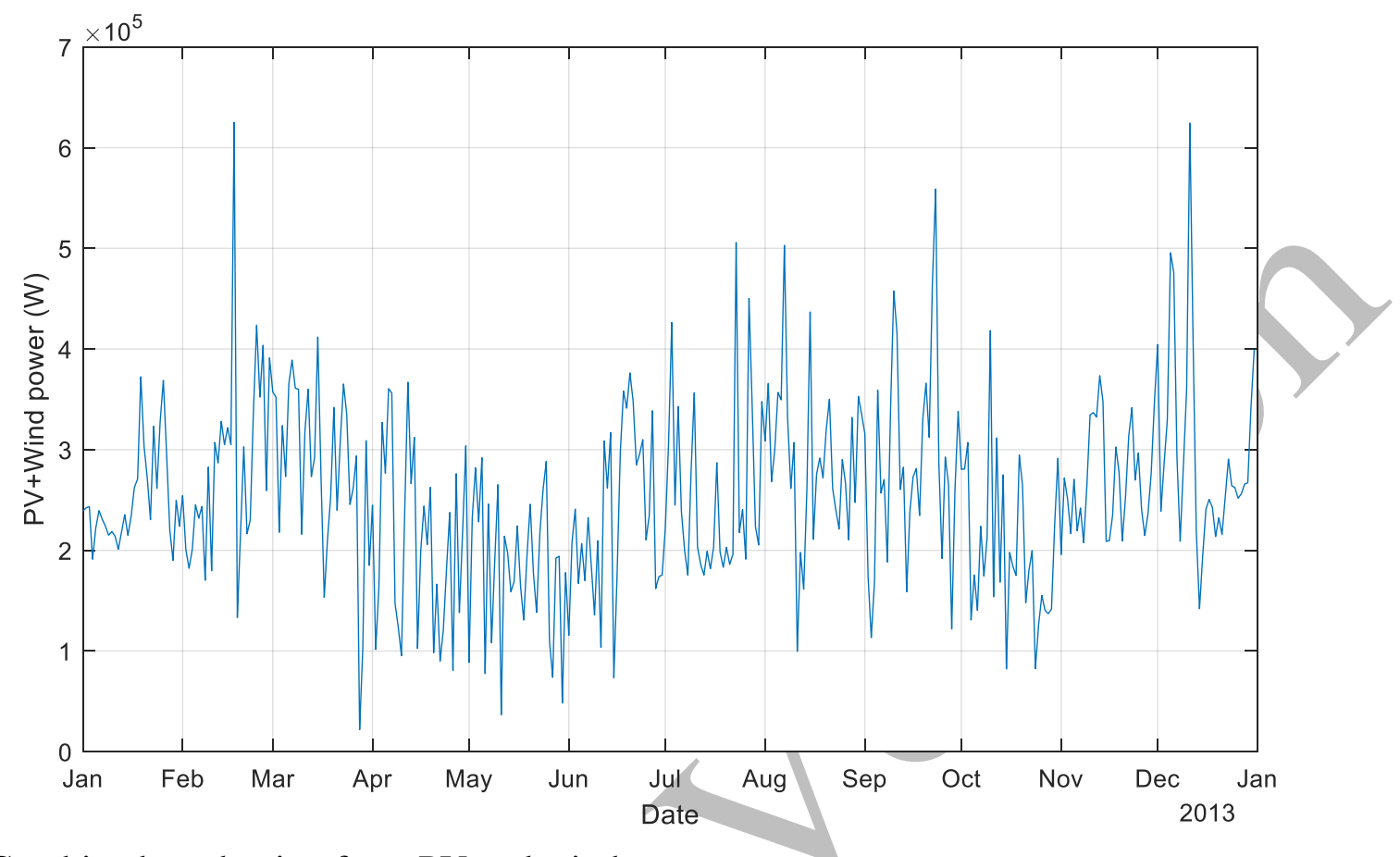

Fig 9: Combined production from PV and wind.

\section{Conclusion}

This paper presented a complementarity study between solar and wind energy potentials. The complementarity was assessed using the Pearson correlation coefficient. The location of solar and wind sources was determined to minimize the Pearson correlation coefficient using PSO algorithm. In the specific case of Benin Republic, we showed that optimal complementarity was obtained between the coastal region in 'Littoral' department for wind and 'Collins' department for solar energy.

The approach developed in this study is important for renewable application projects where different sources are combined for power generation.

\section{References}

[1] "https://www.eia.gov/outlooks/ieo/pdf/0484(2016).pdf."

[2] "http://www.ren21.net/wp-content/uploads/2016/06/GSR_2016_Full_Report.pdf."

[3] Y. Liu, L. Xiao, H. Wang, S. Dai, and Z. Qi, "Analysis on the hourly spatiotemporal complementarities between China's solar and wind energy resources spreading in a wide area," Sci. China Technol. Sci., vol. 56, no. 3, pp. 683-692, Mar. 2013.

[4] A. R. Silva, F. M. Pimenta, A. T. Assireu, and M. H. C. Spyrides, "Complementarity of Brazil's hydro and offshore wind power," Renew. Sustain. Energy Rev., vol. 56, pp. 413-427, Apr. 2016.

[5] C. E. Hoicka and I. H. Rowlands, "Solar and wind resource complementarity: Advancing options for renewable electricity integration in Ontario, Canada," Renew. Energy, vol. 36, no. 1, pp. 97-107, Jan. 2011.

[6] C. N. Awanou, J. M. Degbey, and E. Ahlonsou, "Estimation of the mean wind energy available in Benin (Ex Dahomey)," Renew. Energy, vol. 1, no. 5-6, pp. 845-853, 1991. 
[7] A. B. Akpo, J. C. T. Damada, H. E. V. Donnou, B. Kounouhewa, and C. N. Awanou, "Evaluation de la production énergétique d'un aérogénérateur sur un site isolé dans la région côtière du Bénin,” Rev. Energ. Renouvelables, vol. 18, no. 3, pp. 457-468, 2015.

[8] A. M. Houekpoheha, B. B. Kounouhewa, N. B. Tokpohozin, and C. N. Awanou, "Estimation de la puissance énergétique éolienne à partir de la distribution de Weibull sur la côte béninoise à Cotonou dans le Golfe de Guinée," Rev. Energ. Renouvelables, vol. 17, no. 3, pp. 489-495, 2014.

[9] "Wyoming Weather Web." [Online]. Available: http://weather.uwyo.edu/upperair/. [Accessed: 14-Mar-2017].

[10] U. Pfeifroth et al., "Surface Radiation Data Set - Heliosat (SARAH) - Edition 2." Satellite Application Facility on Climate Monitoring (CM SAF), 2017.

[11] Y. Liu, L. Xiao, H. Wang, L. Lin, and S. Dai, "Investigation on the spatiotemporal complementarity of wind energy resources in China," Sci. China Technol. Sci., vol. 55, no. 3, pp. 725-734, 2012.

[12] M. P. Cantão, M. R. Bessa, R. Bettega, D. H. M. Detzel, and J. M. Lima, "Evaluation of hydro-wind complementarity in the Brazilian territory by means of correlation maps," Renew. Energy, vol. 101, pp. 1215-1225, Feb. 2017.

[13] R. Eberhart and J. Kennedy, "A new optimizer using particle swarm theory," in , Proceedings of the Sixth International Symposium on Micro Machine and Human Science, 1995. MHS '95, 1995, pp. 39-43.

[14] M. Clerc and J. Kennedy, "The particle swarm - explosion, stability, and convergence in a multidimensional complex space," IEEE Trans. Evol. Comput., vol. 6, no. 1, pp. 58-73, Feb. 2002.

[15] Mahamad Nabab Alam, "Particle Swarm Optimization: Algorithm and its Codes in MATLAB," 2016. 